\title{
Factors Affecting Blood Glucose Stability in Type 2 Diabetes Mellitus Patients
}

\author{
Indah Wulandari ${ }^{1, *}$ Kusnanto Kusnanto ${ }^{2}$ Sony Wibisono ${ }^{3}$ Bella Andriani ${ }^{4}$ Andri \\ Restu Wardani ${ }^{5}$ Sela Anugrah Huri ${ }^{6}$
}

\author{
${ }^{1}$ Doctoral Program at Faculty of Nursing Universitas Airlangga Surabaya, Universitas Faletehan Serang \\ ${ }^{2}$ Faculty of Nursing Universitas Airlangga Surabaya \\ ${ }^{3}$ Faculty of Medicine Universitas Airlangga Surabaya \\ ${ }^{4,5,6}$ Bachelor Nursing Program, Faculty of Health Science Universitas Faletehan Serang \\ *Corresponding author. Email: alkaddihan@gmail.com
}

\begin{abstract}
Blood glucose stability is important for type 2 diabetes mellitus patients in order to reduce the risk of co-morbidity due to diabetes mellitus. The stability of blood glucose levels in patients with diabetes mellitus was influenced by several factors such as age, sex, duration of illness, race, diabetes history, knowledge, diet, and activity. This study aims were to determine the factors that correlate with the patient's blood glucose stability. This study use cross-sectional approach with 120 samples recruited using a consecutive approach and used Google forms to collect the data. This study analysis used The Independent t- test and Pearson's correlation test to find out a correlation between variables. Study results shows that most respondents are female, comes from the Sundanese ethnicity, has less five years of diabetes history, have a high education level, have family members with diabetes mellitus, and have co-morbidity. This study also shows that the average of respondent was 41 years old, had a high level of knowledge, was quite active, was adhere to undergo treatment, was adhere to a diet, and had stable blood glucose. Statistical tests shows that age (p-value 0.000), gender (pvalue 0.024), ethnicity (p-value 0.009), level of education (p-value 0.000), co-morbidity (p-value .003), and knowledge (p-value 0.037) affect the blood glucose stability in type 2 Diabetes Mellitus patient. This study does not find the correlation of other variables with the stability of blood glucose which may be related to the physical condition of the patient and other factors.
\end{abstract}

Keywords: adherence, blood glucose control, factors

\section{INTRODUCTION}

Diabetes mellitus is a metabolic disorder caused by impaired insulin secretion, impaired insulin action, or both are characterized by hyperglycemia. Impaired shortterm of blood glucose levels balance that occurs in patients with diabetes mellitus include hypoglycemia, diabetic ketoacidosis, and hyperosmolar non-ketotic syndrome. Hyperglycemia that occurs in the long term contributes to the occurrence of complications in diabetes mellitus patients such as macro and microvascular disorders, also neuropathy disorders [1].

Recent studies had shown that there are essential behaviors by diabetes mellitus patients to control their blood glucose levels, namely, diet adherence, being physically active, monitoring blood sugar regularly, and medication adherence [2]. In addition, problem-solving skills, positive coping skills, and risk reduction behaviors are needed to control blood glucose levels[2]. Behavior is not the only thing that maintains blood glucose stability. Self-efficacy, stress control, and family support are needed to control blood glucose levels in patients with diabetes mellitus [3]-[6].

Analysis of existing studies shows that poor blood glucose control is influenced by age, education, knowledge, and duration of treatment [3], [7]. Other barriers to glucose control found in previous studies are misconceptions that diabetes is caused by spiritual forces or curses, the use of herbal medicines, intentional noncompliance, difficulty changing old habits, and feelings or lack of motivation to exercise, social stigma, and cultural beliefs [8].

Various interventions have been carried out to help patients with diabetes mellitus maintain their blood glucose levels. Education to improve patient knowledge is one of the most frequent interventions by health workers [4][9]. Furthermore, interventions to increase motivation and self-efficacy become other alternatives that are carried out by health workers to help diabetes mellitus patients maintain their blood glucose levels [10]. Other than that, interventions to increase social support 
from families, peers, or health workers who support patients externally [4]. Pre-existing intervention programs were implemented to improve the skills of patients in self-care that have a direct impact on blood glucose control.

This research was conducted to find out how the correlation between internal and external factors of diabetes mellitus patients with the stability of their blood glucose levels. The stability of blood glucose levels in this study refers to the definition of nursing diagnosis from the Indonesian Nursing Diagnosis Standard. Blood glucose level instability, according to the Indonesian Nursing Diagnosis Standard, is the variation in blood glucose levels up or down from the normal range seen from the major and minor symptoms of hypoglycemia and hyperglycemia.

\section{METHOD}

\subsection{Design}

This study used a cross-sectional analysis approach. The independent variables in this study were age, sex, race, knowledge, education, occupation, durations of illness, family history of diabetes, accompanying diseases, diet, activity, and medication adherence. In addition, the independent variable in this study was the stability of blood glucose levels.

\subsection{Participants and Procedures}

The sample in this study was taken using nonprobability consecutive sampling techniques. The results of the calculation of the number of samples obtained 120 respondents with criteria type 2 diabetes mellitus patients who were diagnosed for at least 1 year, understood the questionnaire, and were willing to become respondents.

\subsection{Data Collection}

The sata collection method used Google Forms that were distributed through the social media WhatsApp Group. The selection of data collection methods was based on the Covid-19 pandemic event, so that the method chosen is not at risk in spreading infection from or to respondents. Completion of the questionnaire took 20-30 minutes, and respondents were compensated for telephone credit replacements. The participants' identities were concealed and used for the purpose of data analysis. The independent variables were age, sex, race, education, occupation, duration of illness, family history of diabetes, and history of co-morbidity using scoring dichotomy. In contrast the independent variables of knowledge, diet, activity, and medication adherence use research instruments that have been tested for validity and reliability. The dependent variable is the stability of blood glucose measured using an instrument that is based on the Indonesian Nursing Diagnosis Standard and has been tested for its reliability validity before use.

\subsection{Data Analysis}

The researcher used univariate and bivariate analysis techniques to analysis the data. Univariate analysis was performed after the data normality test of all variables. Univariate analysis results are presented in the form of frequency distribution. The bivariate analysis uses an independent $t$-test to compare the stability of blood glucose between groups.

\section{RESULT}

The study shows that most of the participants were more than 41 years old (58\%), female (60\%), Sundanese ethnicity (52\%), duration of illness less than 5 years $(52 \%)$, higher than junior high school $(77 \%)$, working $(63 \%)$, diabetes mellitus in family history $(56 \%)$, with co-morbidity (69\%) seen in Fig 1.

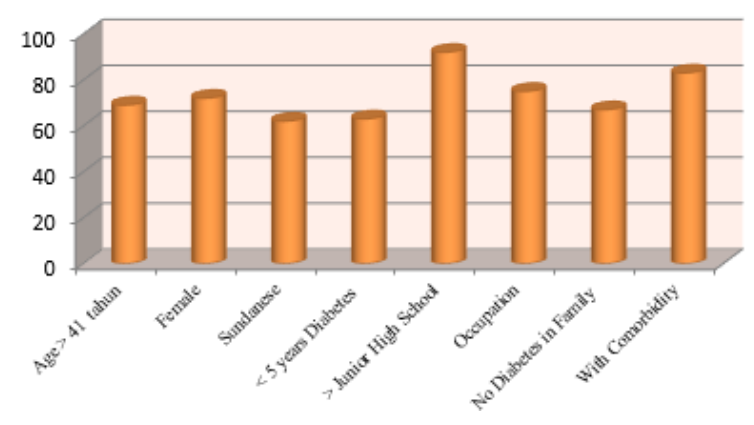

Figure 1 Participants Characteristics

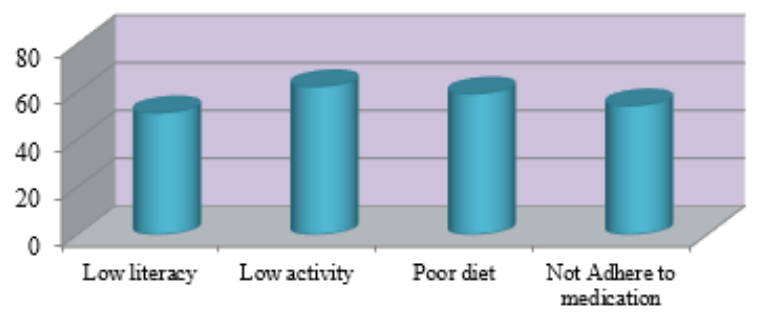

Figure 2 Literacy, Activity, Diet, and Medication of Diabetes Mellitus Patients

Table1. Independent $t$-test results of the stability of blood glucose levels

\begin{tabular}{lll}
\hline $\begin{array}{l}\text { Stability of blood glucose } \\
\text { level }\end{array}$ & Mean (s.d) & $\begin{array}{l}\text { P- } \\
\text { value }\end{array}$ \\
\hline $\begin{array}{l}\text { Age } \geq 41 \text { years } \\
\text { Age }<41 \text { years }\end{array}$ & $\begin{array}{l}18.96(4.45) \\
21.90(3.99)\end{array}$ & $0.000^{\mathrm{a}}$ \\
\hline $\begin{array}{l}\text { Female } \\
\text { Male }\end{array}$ & $\begin{array}{l}20.96(4.32) \\
19.08(4.54)\end{array}$ & $0.024^{\mathrm{a}}$ \\
\hline $\begin{array}{l}\text { Sundanese } \\
\text { Javanese }\end{array}$ & $\begin{array}{l}19.19(4.36) \\
21.38(4.45)\end{array}$ & $0.009^{\mathrm{a}}$ \\
\hline $\begin{array}{l}\text { Have } \geq 5 \text { years of diabetes } \\
\text { history }\end{array}$ & $\begin{array}{l}20.72(4.84) \\
19.75(4.13)\end{array}$ & 0.237 \\
\hline
\end{tabular}




\begin{tabular}{|c|c|c|}
\hline $\begin{array}{l}\text { Stability of blood glucose } \\
\text { level }\end{array}$ & Mean (s.d) & $\begin{array}{l}\text { P- } \\
\text { value }\end{array}$ \\
\hline \multicolumn{3}{|l|}{$\begin{array}{l}\text { Have < } 5 \text { years of diabetes } \\
\text { history }\end{array}$} \\
\hline $\begin{array}{l}\text { Lower than high school } \\
\text { Highest than junior high } \\
\text { school }\end{array}$ & $\begin{array}{l}17.82(3.13) \\
20.93(4.60)\end{array}$ & $0.000^{\mathrm{a}}$ \\
\hline $\begin{array}{l}\text { Occupation } \\
\text { Not occupation }\end{array}$ & $\begin{array}{l}26.20(4.51) \\
20.22(4.51)\end{array}$ & 0.980 \\
\hline $\begin{array}{l}\text { No diabetes in family } \\
\text { history } \\
\text { Diabetes in family history }\end{array}$ & $\begin{array}{l}20.77(4.06) \\
20.07(4.85)\end{array}$ & 0.425 \\
\hline $\begin{array}{l}\text { Have co-morbidity } \\
\text { Do not have co-morbidity }\end{array}$ & $\begin{array}{l}19.46(4.61) \\
21.89(3.73) \\
\end{array}$ & $0.003^{\mathrm{a}}$ \\
\hline $\begin{array}{l}\text { Low knowledge } \\
\text { High knowledge }\end{array}$ & $\begin{array}{l}19.22(4.79) \\
20.94(4.14)\end{array}$ & $0.037^{\mathrm{a}}$ \\
\hline $\begin{array}{l}\text { Poor activity } \\
\text { Good activity }\end{array}$ & $\begin{array}{l}20.82(4.17) \\
19.55(4.79)\end{array}$ & 0.122 \\
\hline $\begin{array}{l}\text { Not adhere to the diet } \\
\text { Adhere to the diet }\end{array}$ & $\begin{array}{l}19.42(4.04) \\
20.97(4.79)\end{array}$ & 0.059 \\
\hline $\begin{array}{l}\text { Not adhere to the } \\
\text { medication } \\
\text { Adhere to the medication }\end{array}$ & $\begin{array}{l}19.70(4.37) \\
20.62(4.57)\end{array}$ & 0.267 \\
\hline
\end{tabular}

This study also showed that a small proportion of participants had poor knowledge (42\%), low activity (52\%), did not adhere to diet (49\%), and did not adhere to medication (45\%) (Fig 2). From all the independent variables tested, it was found that the stability of blood glucose was influenced by age (p-value 0.024$)$, ethnicity (p-value 0.009 ), level of education ( $\mathrm{p}$-value 0,000$)$, comorbidity (p-value 0.003 ), patient knowledge ( $\mathrm{p}$-value $0,000)$, activity (p-value 0.037 ), and diet ( $\mathrm{p}$-value 0.05 ) (table1).

\section{DISCUSSION}

The stability of the blood transition has always been a focus in the care of diabetes mellitus patients. This research recommend to health workers to pay more attention to diabetes mellitus patients who have attended more than 41 years, female, Sundanese race, have low education, have co-morbidity, and have low knowledge, they have more instability in blood glucose level. As a result of our analysis, increasing age consistent to surrender gain and acceptance of disease. This in fact causes them to not comply with diabetes care as they should, for example in diet or medication. As a result, because they have more instability often experience unstable blood sugar.

Diabetes mellitus is influenced age. People above 40 years old are estimated to have a risk of diabetes mellitus [11]. Instability of blood glucose levels had gained with the patients who were more than 40 years old [3], [7], [10]. Insulin was secreted when glucose in the blood rises. Insulin helps glucose from vascular enter the cells to be used in the process of metabolism or stored in the form of glycogen [12]. Pancreatic function decreases in line with age, which causes disruption of glucose metabolism and results in instability of blood glucose levels. The disorder of blood glucose instability that often occurs in patients with diabetes mellitus is hyperglycemia [13], [14]. The results showed that patients often experience symptoms of hyperglycemia such as drowsiness, fatigue, lethargy, increased thirst, frequent urination, and dry mouth. Recent studies had shown that over 40 years, patients have more at risk of hyperglycemia [3], [7].

The results shows obesity, family history of diabetes, knowledge, and education were risk factors for females experiencing blood glucose instability. Female have a greater risk of developing diabetes mellitus due to obesity or a history of giving birth to a baby over 4 kilograms [11]. Women have less muscle mass than men but have a higher adipose tissue mass. There is more free fatty acids and higher intramyocellular lipid content. all these conditions that cause women to experience more insulin resistance which contributes to blood glucose level [15].

The psychological condition of women also affects blood glucose levels. Anxiety to depression is a problem that affects diabetes mellitus found in previous studies [16]. Emotions can affect blood sugar level. Anxiety, fear, even that happy feeling can be stressful sometimes. When one's was stressed, whether it's physical stress or mental stress, bodies will produce hormones such as cortisol that can raise blood glucose even if we haven't eaten. The cortisol, which is continuously produced when a person experiences stress, in the long term becomes a predictive factor for diabetes mellitus [17].

Education also showed a significant correlation with blood glucose levels in this study. Formal education is better than informal education in increasing patient understanding and also towards patient behavior. Education influences the thinking patterns and attitudes of diabetic patients better than the information that is received informally. The level of education was correlates with knowledge. Patients who were illiterate and with informal education have blood glucose instability than those with college/higher education graduates [7]. The information cannot be trusted caused diabetes mellitus patients not to get the right and real information so that it can influence their attitudes and behavior incorrectly [10], [18]. As a result of wrong behavior is instability of blood glucose level.

Ethnicity is one of the factors that influence blood glucose levels, especially for patients with diabetes mellitus. The results of this study show that ethnicity affect blood glucose levels. Previous studies have suggested that ethnicity affects blood glucose levels. It is not yet clear why ethnicity can affect blood glucose levels [19]-[21]. However, this is interesting to investigate 
further and be a natural alarm for certain ethnic groups against the risk of developing diabetes mellitus.

One other thing that increases the risk of instability of blood glucose levels is the presence of co-morbidity. Comorbidity affects one's blood glucose levelblood glucose levels by disrupting the balance of metabolism in the body [11]. The co-morbidity that were found in this study were hypertension and heart disease. Co-morbidity that occurs as a result of diabetes mellitus or at the same time as diabetes mellitus increase the instability of blood glucose levels.

In this study, diet and medication had no relationship with blood glucose stability. Whereas previous research stated that diet and medication affect blood glucose levels [9], [22], [23]. Our analysis, when viewed from the factors related to the stability of blood glucose is the biological condition of the patient for example age, sex, ethnicity, and co-morbidity. This means that biologically, age, sex, ethnicity, and comorbid diseases affect insulin metabolism or glucose use in cells

When viewed from behavior, most respondents showed low adherence to diet and medication. However, both patients who show adherence or do not adhere to their diet and medication are at risk of unstable blood sugar. The weakness in this study is the indicator used in determining the stability of blood glucose. We took stability indicators based solely on the major and minor symptoms listed in Indonesian Nursing Diagnosis Standard. However, no biomarkers such as blood glucose or HbA1C levels are used as indicators of blood glucose stability. This is evidence that a valid biomarker is needed to indicate a person has stable or volatile blood glucose levels.

\section{STUDY LIMITATION}

This study did not use any random blood glucose biomarkers or HbA1C as an indicator of blood glucose stability due to the Covid-19 pandemic which limited researchers from taking data.

\section{CONCLUSION}

The treatment of diabetic patients is influenced by several factors that affect the stability of blood glucose levels. It is important to pay attention to the contribution of each factor by health workers in order to find the best strategy to solve the raised problems. The final result of this strategy is the achievement of glycemic control with blood glucose levels as an indicator.

\section{AUTHORS' CONTRIBUTIONS}

This research is independently funded and has no sponsor interests. This research is a doctoral program research. the last three authors played a role in data collection

\section{ETHICAL APPROVEMENT}

This study pays attention to ethical principles and has received approval from the Health Research Ethics Commission of the Faculty of Nursing Universitas Airlangga number 2058-KEPK.

\section{ACKNOWLEDGMENTS}

Acknowledgments were given to all of the participants who provided their time in the study, Doctoral Program Faculty of Nursing Universitas Airlangga, and Bachelor Nursing Program, Faculty of Health Science Universitas Faletehan Serang.

\section{REFERENCES}

[1] S. C. Smeltzer, B. G. Bare, J. L.Hinkle, kerry H. Cheever, and T. M. Garret, Brunner and suddarth'sText Book of Medical surgical nursing: hand book for. 2010.

[2] S. R. Shrivastava, P. S. Shrivastava, and J. Ramasamy, "Role of self-care in management of diabetes mellitus," J. Diabetes Metab. Disord., vol. 12, no. 1, p. 1, 2013.

[3] M. Badedi et al., "Factors Associated with LongTerm Control of Type 2 Diabetes Mellitus," J. Diabetes Res., vol. 2016, 2016.

[4] L. C. Gomes, A. C. M. Coelho, D. dos S. Gomides, M. C. Foss-Freitas, M. C. Foss, and A. E. Pace, "Contribution of family social support to the metabolic control of people with diabetes mellitus: A randomized controlled clinical trial," Appl. Nurs. Res., vol. 36, pp. 68-76, 2017.

[5] A. A. Lee, J. D. Piette, M. Heisler, and A.-M. M Rosland, "Diabetes distress and glycemic control: The buffering effect of autonomy support from important family members and friends," Diabetes Care, vol. 41, no. 6, pp. 1157-1163, 2018.

[6] S. F. V. Wu, M. C. Lee, S. Y. Liang, Y. Y. Lu, T. J. Wang, and H. H. Tung, "Effectiveness of a selfefficacy program for persons with diabetes: A randomized controlled trial," Nurs. Heal. Sci., vol. 13, no. 3, pp. 335-343, 2011.

[7] G. Fekadu, K. Bula, G. Bayisa, E. Turi, T. Tolossa, and H. K. Kasaye, "Challenges and factors associated with poor glycemic control among type 2 diabetes mellitus patients at nekemte referral hospital, Western Ethiopia," J. Multidiscip. Healthc., vol. 12, pp. 963-974, 2019.

[8] V. Mogre, N. A. Johnson, F. Tzelepis, and C. Paul, "Barriers to diabetic self-care: A qualitative study of patients' and healthcare providers' perspectives,' J. 
Clin. Nurs., vol. 28, no. 11-12, pp. 2296-2308, 2019.

[9] S. S. Bains and L. E. Egede, "Associations between health literacy, diabetes knowledge, self-care behaviors, and glycemic control in a low income population with type 2 diabetes," Diabetes Technol. Ther., vol. 13, no. 3, pp. 335-341, 2011.

[10] O. A. Al-Khawaldeh, M. A. Al-Hassan, and E. S. Froelicher, "Self-efficacy, self-management, and glycemic control in adults with type 2 diabetes mellitus," J. Diabetes Complications, vol. 26, no. 1, pp. 10-16, 2012.

[11] S. C. Smeltzer and B. Bare, Brunner \& Suddarth's Textbook of Medical Surgical Nursing, 10th ed. Philadelphia: Lippincott Williams \& Wilkins, 2004.

[12] S. S. Tate, Anatomy and Physiology, 6th ed. New York: The McGraw-Hill Companies, 2004.

[13] T. Hayashi et al., "Age, gender, insulin and blood glucose control status alter the risk of ischemic heart disease and stroke among elderly diabetic patients," Cardiovasc. Diabetol., vol. 10, pp. 1-12, 2011.

[14] R. M. Cohen, R. S. Franco, E. P. Smith, and J. M. Higgins, "When HbAlc and Blood Glucose Do Not Match: How Much Is Determined by Race, by Genetics, by Differences in Mean Red Blood Cell Age?," J. Clin. Endocrinol. Metab., vol. 104, no. 3, pp. 707-710, 2018.

[15] F. Mauvais-Jarvis, "Gender differences in glucose homeostasis and diabetes," Physiol. Behav. Behav., vol. 187, pp. 20-23, 2018.

[16] S. E. Choi, E. B. Rush, and S. L. Henry, "Negative emotion and risk for type 2 diabetes among Korean immigrants," Diabetes Educ., vol. 39, no. 5, 2013.

[17] R. A. Hackett, M. Kivimäki, M. Kumari, and A. Steptoe, "Diurnal cortisol patterns, future diabetes, and impaired glucose metabolism in the whitehall II cohort study," J. Clin. Endocrinol. Metab., vol. 101, no. 2, pp. 619-625, 2016.

[18] M. Peimani, F. Monjazebi, R. GhodssiGhassemabadi, and E. Nasli-Esfahani, "A peer support intervention in improving glycemic control in patients with type 2 diabetes," Patient Educ. Couns., vol. 101, no. 3, pp. 460-466, 2018.

[19] W. H. Herman and R. M. Cohen, "Racial and ethnic differences in the relationship between HbA1c and blood glucose: Implications for the diagnosis of diabetes," J. Clin. Endocrinol. Metab., vol. 97, no. 4, pp. 1067-1072, 2012.

[20] Y. J. Cheng et al., "Prevalence of Diabetes by Race and Ethnicity in the United States, 2011-2016,"
JAMA - J. Am. Med. Assoc., vol. 322, no. 24, pp. 2389-2398, 2019.

[21] K. Matsushita, O. Tang, and E. Selvin, “Addressing Challenges and Implications of National Surveillance for Racial/Ethnic Disparities in Diabetes," Am. Med. Assoc., vol. 322, no. 24, pp. 2387-2388, 2019.

[22] A. J. Ahola and P. H. Groop, "Barriers to selfmanagement of diabetes," Diabet. Med., vol. 30, no. 4, pp. 413-420, 2013.

[23] R. A. Pamungkas, K. Chamroonsawasdi, and P. Vatanasomboon, "A systematic review: Family support integrated with diabetes self-management among uncontrolled type II diabetes mellitus patients," Behav. Sci. (Basel)., vol. 7, no. 3, pp. 117, 2017. 